\title{
Transgender Surgery: A Review Article
}

\author{
(1) Kahraman Berkhan Yılmaz'1, (D) Kamil Fehmi Narter² \\ 'Acıbadem Mehmet Ali Aydınlar University Faculty of Medicine, Department of Plastic and Recontructive Surgery, Istanbul, Turkiye \\ 2Acıbadem Kadıköy Hospital, Clinic of Urology, İstanbul, Turkiye
}

What's known on the subject? and What does the study add?

Transgender surgeries are complex and multidisciplinary procedures. This review aimed to summarize these operations for our colleagues according to the current literature.

\begin{abstract}
Transgender surgeries are required to correct some congenital genital defects, reconstruct genital trauma, amputate, treat cancer (e.g., penile cancer), or within a wide perspective to treat gender dysphoria. Literature about gender-affirming surgery is limited; however, surgeries for transgender patients have been done almost for a century. Evidence concerning both male-to-female and female-to-male surgeries has limitations such as insufficient controlled studies, validated assessment measures, and properly controlled groups. Transgender surgeries are mostly required to treat gender dysphoria. The community modernization and more acceptance of transgender citizens in societies have increased the demand for these surgeries within recent years. Increased numbers of patients and advanced surgical options that are available for gender reassignment surgery have made this subject an important consideration for research. Modern surgical techniques with the support of other auxiliary therapy modalities (e.g., hormonal therapy) create satisfactory results for patients; however, these therapies cause many complications as well. In the future, more transgender patients are expected, thus we have to master the subject to treat their problems, most of which probably will be related to surgery complications. This review aimed to summarize transgender surgery, especially genital reconstructive techniques for related specialties to better understand its recent update according to actual literature.
\end{abstract}

Keywords: Transgender, gender dysphoria, gender-affirming

\section{Introduction}

Gender dysphoria term was introduced in the Diagnostic and Statistical Manual of Mental Disorders-5 in 2013. It is estimated that $0.5-1.3 \%$ of the population in the United States of America has gender dysphoria (1). Although it may seem a very new concept, transgender surgery has been done for almost over a century. Surgical treatment of transgender patients is a series of consecutive operations supported with various treatment modalities. The content of these surgical techniques covers multiple complex and challenging operations. Before surgical treatment starts, a long period is necessary for physiological and endocrinological preoperative preparations. Therefore, many specialists perform these surgeries in universities or fully equipped complex utilities, which have all needed specialists. These kinds of surgeries are of interest to many specialties, such as plastic and reconstructive surgery, urology, obstetrics and gynecology, psychiatry, forensic medicine, genetic, and endocrinology. Many countries have authorized the decision to perform these operations in medical centers and committees that include several specialists. In the childhood period, congenital genital abnormalities can be reconstructed but in adulthood, other etiological problems, such as gender dysphoria or trauma, can be treated by these operations. Transgender operations contain two main groups: Male-to-female (MTF) and female-to-male (FTM) surgeries. According to literature, MTF transsexuals are four times more frequent than FTM $(2,3)$. Transsexualism was described by Harry Benjamin in 1966 (4).

Correspondence: Kahraman Berkhan Yılmaz MD, Acıbadem Mehmet Ali Aydınlar University Faculty of Medicine, Department of Plastic and Recontructive Surgery, İstanbul, Turkiye

Phone: +90 5322775685 E-mail: berkhan.yilmaz@acibadem.com ORCID-ID: orcid.org/0000-0001-5042-5857

Received: $12.06 .2021 \quad$ Accepted: 10.09 .2021

Cite this article as: Yılmaz KB, Narter KF. Transgender Surgery: A Review Article. J Urol Surg 2021;8(4):227-233.

${ }^{\circ}$ Copyright 2021 by the Association of Urological Surgery / Journal of Urological Surgery published by Galenos Publishing House. 
Pediatric endocrinologist C. Migeon and psychologist J. Money were focused on intersexed children with ambiguous genitalia in 1966 and the first Gender Identity Clinic was described at Johns Hopkins University on the same date. Currently, the World Professional Association for Transgender Health is the pioneer institution that declared the standards of care, which is regularly updated (2). The etiological factors of transsexualism can be classified as biological (genetic and neuroanatomic) and psychological (environmental and internal).

Transgender surgeries are required mostly to treat gender dysphoria. Before the surgical operations, psychosocial evaluation is very important in the decision-making process (5). In most countries, including our country, candidate patients for this interchange treatment should have hormone replacement treatment under the supervision of a psychiatrist and an endocrinologist for at least 2 years. Patients are expected to live and work in the new gender role to obtain real-life experience of the opposite sex. Evaluation of a patient's body image, goals, and expectations is very crucial. After the completion of the preparation stage, the surgical treatment must be planned. In surgical treatment, efforts are made to achieve mental health, aesthetics, and functionality together. The general plastic and reconstructive surgery principles should always be considered in these operations because these operations have a considerable amount of complication rates.

Hormone-sensitive cancers (breast and prostate) and human immunodeficiency virus infection rates of transgender patients are higher than the normal population. Thus, the postoperative follow-up period is so crucial. Not only surgical but also physical and mental follow-up must be considered by the medical staff. Nowadays, linguistics/voice therapy, mental health, fertility, and sexuality topics are more researched for these patients.

This review aimed to summarize transgender surgical techniques especially genital surgeries for related specialties according to the actual literature (Table 1).

\section{MTF Surgery}

MTF surgery contains non-genital surgeries, such as breast augmentation, vocal cord, and throat surgery (tracheal cartilage shave), facial feminization surgery, and genital surgeries, such as orchidectomy, penectomy, labioplasty, clitoroplasty, and vaginoplasty (Figure 1).

\section{Genital Surgery}

\section{Vaginoplasty and Orchiectomy}

The Hirschfeld Institute for sexual science performed the first transgender vaginoplasty in 1931. The main purpose of vaginoplasty is to create a functional cavity in the pelvis or perineum that also allows proper urination. This neovaginal cavity is created between the prostate and rectum. Vaginoplasty and orchiectomy are made together to take the advance of having more tissue to use for genital reconstruction. For the new vagina, the penile skin flap is ideal due to its properties like being smooth, hairless, elastic, and thin. Ideal dimensions of neovagina are $10 \mathrm{~cm}$ in depth and $30 \mathrm{~mm}$ in length and without introital stenosis (6). After the removal of the corpus spongiosum and testicles, a vaginal cavity is created, and the penile (with scrotal) skin flaps are used to cover the inner lining of this neovagina. The disadvantage of the penile flap is its insufficient size, especially for small penis sizes. This flap has fewer tendencies to contract than skin grafts. Postoperative neovaginal dilation is advised for at least 1 year to prevent introital stenosis and neovaginal shrinkage. If the size of the penile flap is insufficient to cover the neovaginal cavity, skin grafts are used. In this context, flaps can be obtained from the thigh (i.e., gracilis flap) or bowel for vaginal reconstruction. For a vaginoplasty with bowel, the sigmoid is mostly the first choice. Intestinal vaginoplasty can be preferable especially for secondary vaginoplasties. The advantages of using a rectosigmoid part are its length and texture, which are very similar to the vaginal lining. One major disadvantage of intestinal vaginoplasty is

\begin{tabular}{|l|l|}
\hline \multicolumn{2}{|l|}{ Table 1. Overview of surgical procedures } \\
\hline Male-to-female surgery & Female-to-male surgery \\
\hline Facial feminization surgery & $\begin{array}{l}\text { Facial masculinization } \\
\text { surgery }\end{array}$ \\
\hline $\begin{array}{l}\text { Voice surgery and } \\
\text { chondrolaryngoplasty }\end{array}$ & - \\
\hline Breast augmentation & Subcutaneous mastectomy \\
\hline Orchiectomy & Testicular prostheses \\
\hline Vaginoplasty & $\begin{array}{l}\text { Phalloplasty: Free radial } \\
\text { forearm flap, pedicled } \\
\text { anterolateral thigh flap, } \\
\text { myocutaneous gracilis flap, } \\
\text { fibula flap, metoidioplasty, } \\
\text { external prosthesis }\end{array}$ \\
\hline
\end{tabular}

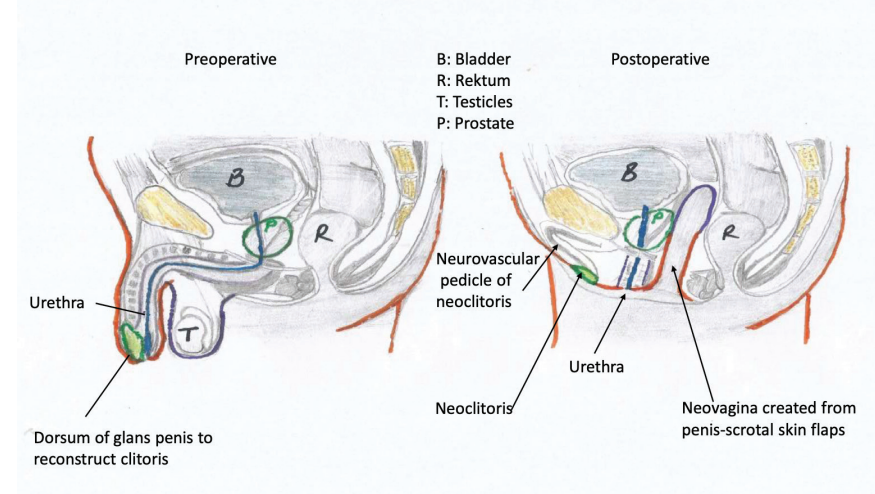

Figure 1. Schematic drawing of MTF surgery

MTF: Male-to-female 
excessive discharge, which may be a social problem. In addition to this, the need for laparotomy and bowel anastomosis, which increase the risk of postoperative ileus.

As a summary, the most preferred MTF genital reconstruction sequence has 5 major steps as penile disassembly and bilateral orchiectomy, neovaginal cavity construction, labia majora creation, and female urethral meatus and clitoris reconstruction $(7,8)$.

\section{Clitoroplasty}

Clitoroplasty, especially from the glans penis, was described by Rubin (9). The neurovascular bundle must be protected for postoperative well sexual satisfaction. The dorsal section of the glans is reduced by excising the central ventral tissue, leaving the sides of the glans intact. Sides are sutured together to obtain the conical shape of the neoclitoris, which is placed in front of the neourethra.

\section{Labioplasty}

Labioplasty is a technique that creates labia majora and minora from tissue remnants after vaginoplasty. Labia majora is mostly reconstructed from the remnants of scrotal skin flaps after orchiectomy is done. Scrotal flaps are reshaped around the newly reconstructed vagina to simulate labia majora. Labia minora is mostly reconstructed from the prepuce. When the penile inversion technique is used for vaginal reconstruction, the tissue may be inadequate to reconstruct the labia minora. However, if vaginoplasty is done with bowel flaps, there is plenty of tissue to reconstruct the labia minora and clitoral prepuce.

\section{Urethroplasty}

Urethrostomy is the reopening technique of shortened urethra to skin. The urethra is divided at the proximal bulb level and the urothelium is sutured to the anterior skin flap. This operation has some early complications, such as urethral meatal stenosis, the unsatisfactory direction of micturition, and residual erectile tissue due to corpus spongiosum remnants.

The most frequent early complications of all MTF operations are bleeding from operation sites, rectal fistula into the neovagina, and neovaginal prolapse or graft/flap loss due to hematoma. Late complications of these operations are meatal stenosis due to scar contracture and incontinence due to retention of urine. In addition, vaginal stenosis and hair growth within the neovagina can be seen as late postoperative complications due to the lack of regular follow-up.

A rectal-neovaginal fistula can occur due to traction or injury during the operation. Rectovaginal fistula incidence was reported at $0.8 \%$ by van der Sluis et al. (10). One other complication of these operations is the urethroneovaginal fistula. Its incidence was reported at 0.8-3.9\% (11-14). After the vaginoplasty operation, one of the most serious complications is urethral stenosis, especially at the meatal level (incidence range $1-40 \%)(13-16)$. Neovaginal stenosis may occur in 7\% (1-12\%) of patients $(17,18)$. Other complications were reported, such as urethral bulb bulge and cosmetic abnormality of the clitoral or labial outlook.

Before the vaginoplasty, bowel preparation and permanent hair removal are recommended. Estrogen treatment should be stopped 2 weeks before the surgery and preoperative anticoagulation should be started. Neourethral catheterization and pressure dressing are necessary for the postoperative period. Vaginal dilatation and lubrication are important procedures to protect against stenosis $(3,19)$. After the MTF surgery, it should be kept in mind that patients are still at risk for benign prostatic hyperplasia and prostate cancer due to remnant in situ prostate (20). Another important risk of the neovagina is the development of squamous cell carcinoma due to penile skin (21). Therefore, patients should be followed up regularly for a long time.

Venous thromboembolic disease (VTE) is another complication of MTF surgery. Cross-sex hormone replacement therapy allows individuals to develop secondary sex characteristics to feel their new identity. But this treatment, especially estrogen use, has a major complication that includes VTE, as well as coronary artery disease, stroke, and cancer formation. If anytime during the follow-up period, a VTE is diagnosed, the hormone replacement therapy is immediately stopped, and anticoagulant therapy must be started (22).

Non-genital Surgery:

1. Facial Feminization Surgery

- Chin surgery

- Eyelid surgery

- Rhinoplasty

- Forehead reshaping

- Hair restoration

2. Chondrolaryngoplasty and Voice Surgery

3. Breast Augmentation (breast reconstruction)

- Silicone implants

- Fat grafts.

As non-genital surgeries listed here are out of the scope of a urological journal, they will be written here only as names.

\section{FTM Surgery}

FTM procedures can also be grouped as non-genital and genital operations. Non-genital procedures include mastectomy, nipple reconstruction, and facial masculinization, whereas 
genital procedures include hysterectomy, oophorectomy, vaginectomy or colpectomy, and penis reconstruction. Besides, at the preoperative period, some of the masculine traits can be obtained by testosterone replacement treatment (over 1 year), such as voice, facial and body hair growth, muscle growth, and clitoral hypertrophy. Most often, after the hormonal treatment period, genital surgical operations of these patients are required (Figure 2).

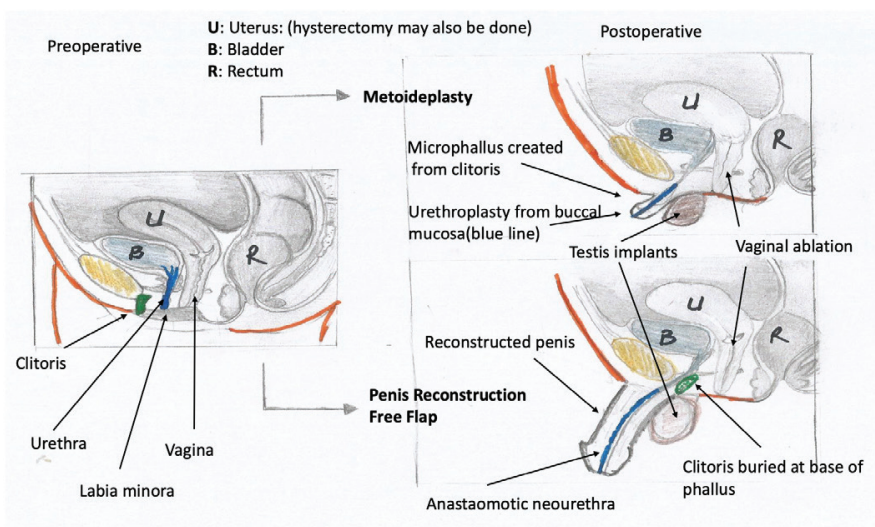

Figure 2. Schematic drawing of FTM surgery

FTM: Female-to-male

\section{Genital Surgery}

Metoidioplasty, phalloplasty, penile prosthesis implantation, and scrotal reconstruction are done for male genital and perineal reconstruction. These operations aimed to include micturation in a standing position, well cosmetic appearance, and adequate sexual performance.

\section{Penile Reconstruction}

Metoidioplasty is a procedure that uses the clitoris that is overdeveloped by hormonal treatment (testosterone replacement) to construct a new small phallus. This technique was first introduced by Lebovic and Laub (23). The small size of the new phallus is the main problem $(5-7 \mathrm{~cm})$ of this procedure. Contrarily, advantages of this technique are well tactile and erogenous sensation, erectile tissue without prostheses, and limited scar formation. Metoidioplasty contains chordee release, neurovascular pedicle reposition, and ventral phallus skin closure. In this operation, the labia minora flaps are preserved and used as additional coverage over the native urethra to ring flap anastomosis. Additionally, full metoidioplasty includes a vaginectomy, urethroplasty (urethral reconstruction), scrotoplasty, and perineal reconstruction. According to a metaanalysis reported, the metoidioplasty-associated urethral complication rate is approximately $25 \%$ (24). In addition, urethral strictures and fistulas are common and the incidence rate is approximately $50 \%(25,26)$. Neophallus has to be checked often with Doppler ultrasonography at the postoperative period for blood supply.

Phalloplasty is another option for cosmesis, which brings the adequate size of new phallus (pedicle flap phalloplasty or free flap phalloplasty). The neourethra, which also has to be reconstructed, opens to the tip of the neophallus. Vaginal epithelium and skin can be used to create a neourethra within chosen flaps. Many flap options are available to give shape to the penis; tubed pedicle flaps can be obtained from the abdomen (suprapubic phalloplasty) or free flaps can be prepared from the radial forearm free flap (RFFF), anterolateral thigh (ALT), fibula, and musculocutaneous latissimus dorsi free flap, tibial free flap, and abdominal or groin pedicle flap. Phalloplasty was done in 1936 by Nikolaj Bogoraz (27). Bogoraz reconstructed the first functional transgender neophallus using a tubed abdominal flap and autologous rib cartilage. H. Gilles described a new technique with the construction of the neourethra by a roller tube from the abdominal wall in 1946 (28). Kaplan (29) described another procedure with neourethra formed from the scrotal raphe and well sensitive neophallus innervated from the genitofemoral branches. Orticochea described a musculocutaneous gracilis flap with the cutaneous branch of the obturator nerve for phalloplasty (30). Groin flap was used by McGregor and Jackson (31). Hester et al. (32) demonstrated a single-stage total penile reconstruction with bilateral gracilis muscle flaps, and urethral reconstruction was utilized from a full-thickness skin graft in 1978. In 1982, Song developed the first successful RFFF (33). However, his technique was two-staged procedure, which includes phalloplasty and urethroplasty, separately. In 1984, Chang and Hwang (34) described one staged RFFF technique with good functional and cosmetic results using microsurgical techniques. This method was named "tube-within-a-tube" by the authors. Ten years later, Hage and De Graaf (35) changed the ideal technique definition as one-stage procedure, which created a neourethra compatible with standing micturition and suitable for prosthetic insertion. All techniques are summarized in Table 2. Many other free flap phalloplasty procedures have been described afterward like lateral arm, radial forearm osteocutaneous, free osteofasciocutaneous fibula, island tensor fasciae latae, scapular skin, ALT, superficial circumflex iliac artery perforator, musculocutaneous latissimus dorsi free, and single pedicled ALT flaps. Today, the forearm (radial) free flaps are preferable for phalloplasty in one staged or twostaged fashion. In this technique, the radial artery and the cutaneous antebrachial nerves are crucial. The radial vessels are anastomosed to the femoral artery and the long saphenous vein and cutaneous nerves are sutured to the dorsal nerve of the clitoris and the ileoinguinal nerve under a microscope view (36). Neophallus has two parts as pars pendulas (distal urethra) and pars fixa (proximal urethra). Pars fixa is created from the labia minora and vaginal epithelium, around the urethral 


\begin{tabular}{|c|c|}
\hline Technique & Materials and Methods \\
\hline $\begin{array}{l}\text { Metoidioplasty (G.S.Lebovic } \\
\text { and D.R.Laub, 1999) }\end{array}$ & $\begin{array}{l}\text { Clitoris and hormonal treatment } \\
\text { (testosterone replacement } \\
\text { therapy) }\end{array}$ \\
\hline \multicolumn{2}{|l|}{ Phalloplasty } \\
\hline Phalloplasty (N.Bogoraz, 1936) & $\begin{array}{l}\text { Tubed abdominal flap and } \\
\text { autologous rib cartilage }\end{array}$ \\
\hline $\begin{array}{l}\text { Phalloplasty with neourethra } \\
\text { (H.Gilles, 1946) }\end{array}$ & $\begin{array}{l}\text { The construction of the } \\
\text { neourethra by a roller tube from } \\
\text { abdominal wall }\end{array}$ \\
\hline $\begin{array}{l}\text { Phalloplasty with neourethra } \\
\text { (I.Kaplan, 1971) }\end{array}$ & $\begin{array}{l}\text { The neourethra formed from } \\
\text { scrotal raphe and well sensitive } \\
\text { neophallus innervated from } \\
\text { genitofemoral branches }\end{array}$ \\
\hline $\begin{array}{l}\text { Phalloplasty with neourethra } \\
\text { (M.Orticochea, 1972) }\end{array}$ & $\begin{array}{l}\text { Musculocutaneous gracilis } \\
\text { flap with cutaneous branch of } \\
\text { obturator nerve }\end{array}$ \\
\hline $\begin{array}{l}\text { Phalloplasty with neourethra } \\
\text { (I.A.McGregor and I.T.Jackson, } \\
\text { 1972) }\end{array}$ & Groin flap for phalloplasty \\
\hline $\begin{array}{l}\text { Single stage total penile } \\
\text { reconstruction (T.R.Hester, } \\
\text { 1978) }\end{array}$ & $\begin{array}{l}\text { Bilateral gracilis muscle flaps } \\
\text { and urethral reconstruction was } \\
\text { utilized from a full thickness skin } \\
\text { graft }\end{array}$ \\
\hline $\begin{array}{l}\text { Free flap phalloplasty, two } \\
\text { stages (R.Song, 1982) }\end{array}$ & $\begin{array}{l}\text { Radial forearm free flap (RFFF) } \\
\text { for phalloplasty, two stages } \\
\text { (phalloplasty and urethraplasty) }\end{array}$ \\
\hline $\begin{array}{l}\text { Free flap phalloplasty with } \\
\text { microsurgery, one stage } \\
\text { (T.S.Chang and W.Y.Hwang, } \\
\text { 1984) }\end{array}$ & $\begin{array}{l}\text { One staged RFFF technique (tube- } \\
\text { within-a-tube method) }\end{array}$ \\
\hline $\begin{array}{l}\text { Free flap phalloplasty with } \\
\text { microsurgery, one stage } \\
\text { (J.Hage and F.H.De Graaf, } \\
\text { 1993) }\end{array}$ & $\begin{array}{l}\text { One stage RFFF technique, } \\
\text { neourethra compatible to } \\
\text { standing micturition, suitable for } \\
\text { prosthetic insertion }\end{array}$ \\
\hline
\end{tabular}

catheter, and this urethral part is joined to the inner tube in the neophallus. The clitoris is usually left in place at the base of the neophallus for sexual sensation and orgasm. Moreover, the Norfolk technique and its modifications can be used (rolled up skin flaps and skin grafts) for almost normal appearing glans and coronal sulcus (glansplasty and coronaplasty) $(37,38)$.

The ideal flap reconstruction technique has to contain a good cosmetic shape and must be suitable for prosthesis insertion and functional in voiding and sexual activities. In addition, a good sensation that is enough for orgasm must be obtained and with a low morbidity rate for the donor site (donor scar). Preferably, single staged techniques which have constant vascular and neural anatomy have to be chosen. If a skin flap is to be selected, care should be taken not to disturb the blood supply of the vascular pedicle.

These operations have a high risk of having urethral stenosis, urethral fistula, and postmicturition dribble. The complication rate of FTM surgery is higher than MTF surgery (40\% vs. 25\%). A suggested body mass index cutoff is $35 \mathrm{~kg} / \mathrm{m}^{2}$ for patients desiring RFFF phalloplasty (39).

A penile prosthesis has to be placed to provide an adequate erection. After placing the prosthesis, it has to be anchored to the pelvic bone. Modern techniques prefer to use either a semirigid or inflatable prosthesis for implantation. It is recommended to implant a penile prosthesis into a sensate neophallus, as insensate coverage significantly increases the risk for implant erosion. Thus, waiting for the protective tactile sensation of the neophallus is very important. This process usually takes approximately 9 months. It will be better to wait for 1 year before considering implantation (40). Bilateral perineal incisions are ideal for implant insertion instead of making an incision on the reconstructed penis. If an inflatable device is chosen, the reservoir is placed in the space of Retzius with a separate abdominal incision to avoid injury to the flap vasculature.

\section{Scrotoplasty}

Scrotoplasty is the reconstruction of a new scrotum for testicle prosthesis. A new scrotum can be created from the labia majora tissue. Additionally, monsplasty and dermatolipectomy can be required.

Complications of FTM surgery are common, such as open wounds, urinary tract or skin infections, vascular thrombosis, hematomas, penile implant erosion, and infections. If urethral strictures or fistulas happen, these patients will require surgical repair 3-6 months after the phalloplasty. The highest risk for a urethral fistula or stricture formation is at PF-PP urethral anastomosis site and meatal level. Fistulas that are small and persist beyond 3-4 months postoperatively can be repaired primarily. Larger fistulas ( $>5 \mathrm{~mm}$ ) can be treated with skin grafts or mucosal grafts that are similar to the urethral epithelium.

Penile transplantation (penis allotransplantation) is not currently used for transgender surgery. Few cases of penile transplantation were reported after traumatic amputation and oncological resection. The first successful human penis transplantation was performed in 2015 in South Africa to reconstruct the penis of a biological man who developed a complication from circumcision for which penile amputation was necessary (41). But there are still many unsolved ethico-legal issues and problems due to immunosuppression. The high cost of operation and the risks of lifelong usage of immunosuppression are still argument subjects for a non-life-saving procedure.

Non-genital Surgery:

\section{Facial masculinization surgery}

\section{Subcutaneous mastectomy}

3. Nipple-areola reconstruction (reduction). 
As non-genital surgeries listed here are out of the scope of a urological journal, they will be written here only as names.

\section{Conclusion}

Gender dysphoria is no more a social problem in developed countries and patients more and more feel confident to seek gender reassignment surgery. However, transgender surgeries continue to be the most challenging and complex surgical procedures. In addition, these surgeries have very high complication rates. Assessment of the quality of life, long-term surgical follow-ups, and satisfactory outcomes are necessary for rational progress. The increasing interest in transgender surgery and advancement in medical technologies are contributing to this topic. Expert centers with multidisciplinary clinics are needed for successful outcomes. Every specialist involved in these subjects has to be more informed on these topics. Moreover, better-designed and larger-scale cohort studies are needed.

\section{Acknowledgements}

All authors contributed to concepts, design, definition of intellectual content, literature search, clinical studies, data acquisition, data analysis, manuscript preparation, manuscript editing, and manuscript review. All author took responsibility of the integrity of the work as a whole from inception to published article and were designated as "guarantor".

Peer-review: Internally peer-reviewed.

\section{Authorship Contributions}

Surgical and Medical Practices: K.B.Y., Concept: K.B.Y., F.N., Design: F.N., Literature Search: K.B.Y., F.N., Writing: K.B.Y., F.N.

Conflict of Interest: No conflict of interest was declared by the authors.

Financial Disclosure: The authors declared that this study received no financial support.

\section{References}

1. Zucker KJ. Epidemiology of gender dysphoria and transgender identity. Sex Health 2017;14:404-411.

2. Meyer W, Bockting WO, Cohen-Kettenis PT. The Harry Benjamin Gender Dysphoria Association's standards of care for gender identity disorders, 6th version. Journal of Psychology \&t Human Sexuality 2002;13:1-30.

3. Selvaggi G, Ceulemans $P$, De Cuypere G, VanLanduyt $K$, Blondeel $P$, Hamdi $\mathrm{M}$, Bowman C, Monstrey S. Gender identity disorder: general overview and surgical treatment for vaginoplasty in male-to-female transsexuals. Plast Reconstr Surg 2005;116:135e-145e.

4. Benjamin H. (ed.) The Transsexual Phenomenon Julian Press Inc., New York: 1966. p. 1-156.

5. Ettner R. Mental Health Evaluation for Gender Confirmation Surgery. Clin Plast Surg 2018;45:307-311.
6. Beek TF, Cohen-Kettenis PT, Kreukels BP. Gender incongruence/gender dysphoria and its classification history. Int Rev Psychiatry 2016;28:5-12.

7. Amend B, Seibold J, Toomey P, Stenzl A, Sievert KD. Surgical reconstruction for male-to-female sex reassignment. Eur Urol 2013;64:141-149.

8. Dreher PC, Edwards D, Hager S, Dennis M, Belkoff A, Mora J, Tarry S, Rumer $\mathrm{KL}$. Complications of the neovagina in male-to-female transgender surgery: A systematic review and meta-analysis with discussion of management Clin Anat 2018;31:191-199.

9. Rubin S0. Sex-reassignment surgery male-to-female. Review, own results and report of a new technique using the glans penis as a pseudoclitoris. Scand J Urol Nephrol Suppl 1993;154:1-28.

10. van der Sluis WB, Bouman MB, Buncamper ME, Pigot GLS, Mullender MG, Meijerink WJHJ. Clinical Characteristics and Management of Neovaginal Fistulas After Vaginoplasty in Transgender Women. Obstet Gynecol 2016;127:1118-1126.

11. Jacoby A, Maliha S, Granieri MA, Cohen O, Dy GW, Bluebond-Langner R, Zhao LC. Robotic Davydov Peritoneal Flap Vaginoplasty for Augmentation of Vaginal Depth in Feminizing Vaginoplasty. J Urol 2019;201:1171-1176.

12. Hadj-Moussa M, Ohl DA, Kuzon WM Jr. Feminizing Genital GenderConfirmation Surgery. Sex Med Rev 2018;6:457-468.e2.

13. Reed HM. Aesthetic and functional male to female genital and perineal surgery: feminizing vaginoplasty. Semin Plast Surg 2011;25:163-174.

14. Rossi Neto R, Hintz F, Krege S, Rubben H, Vom Dorp F. Gender reassignment surgery--a 13 year review of surgical outcomes. Int Braz J Urol 2012;38:97107.

15. Perovic SV, Stanojevic DS, Djordjevic ML. Vaginoplasty in male transsexuals using penile skin and a urethral flap. BJU Int 2000;86:843-850.

16. Krege $\mathrm{S}$, Bex A, Lümmen $\mathrm{G}$, Rübben $\mathrm{H}$. Male-to-female transsexualism: a technique, results and long-term follow-up in 66 patients. BJU Int 2001;88:396-402.

17. Jiang DD, Gallagher S, Burchill L, Berli J, Dugi D 3rd. Implementation of a Pelvic Floor Physical Therapy Program for Transgender Women Undergoing Gender-Affirming Vaginoplasty. Obstet Gynecol 2019;133:1003-1011.

18. Horbach SE, Bouman MB, Smit JM, Özer M, Buncamper ME, Mullender MG. Outcome of Vaginoplasty in Male-to-Female Transgenders: A Systematic Review of Surgical Techniques. J Sex Med 2015;12:1499-1512.

19. Morrison SD, Satterwhite T, Grant DW, Kirby J, Laub DR Sr, VanMaasdam J. Long-Term Outcomes of Rectosigmoid Neocolporrhaphy in Male-to-Female Gender Reassignment Surgery. Plast Reconstr Surg 2015;136:386-394.

20. Jarolím L, Šedý J, Schmidt M, Naňka O, Foltán R, Kawaciuk I. Gender reassignment surgery in male-to-female transsexualism: A retrospective 3-month follow-up study with anatomical remarks. J Sex Med 2009;6:16351644.

21. Schober JM. Cancer of the neovagina. J Pediatr Urol 2007;3:167-170

22. Goldstein Z, Khan M, Reisman T, Safer JD. Managing the risk of venous thromboembolism in transgender adults undergoing hormone therapy. J Blood Med 2019;10:209-216.

23. Lebovic GS, Laub DR. Metoidioplasty. In: Ehrlich R.M. Alter G.J. Reconstructive and plastic surgery of the external genitalia. WB Saunders Co, Philadelphia: 1999: p. 355.

24. Frey JD, Poudrier G, Chiodo MV, Hazen A. A Systematic Review of Metoidioplasty and Radial Forearm Flap Phalloplasty in Female-to-male Transgender Genital Reconstruction: Is the "Ideal" Neophallus an Achievable Goal? Plast Reconstr Surg Glob Open 2016;4:e1131.

25. Takamatsu A, Harashina T. Labial ring flap: a new flap for metaidoioplasty in female-to-male transsexuals. J Plast Reconstr Aesthet Surg 2009;62:318325.

26. Djordjevic ML, Bizic M, Stanojevic D, Bumbasirevic M, Kojovic V, Majstorovic M, Acimovic M, Pandey S, Perovic SV. Urethral Lengthening in metoidioplasty 
(female-to-male sex reassignment surgery) by combined buccal mucosa graft and labia minora flap. Urology 2009;74:349-353.

27. Schultheiss D, Gabouev Al, Jonas U. Nikolaj A. Bogoraz (1874-1952): pioneer of phalloplasty and penile implant surgery. J Sex Med 2005;2:139-146.

28. Nair R, Sriprasad S. 1129 Sir Harold Gillies: Pioneer of phalloplasty and the birth of uroplastic surgery. J Urol 2010:183:e437.

29. Kaplan I. A rapid method for constructing a functional sensitive penis. Br J Plast Surg 1971;24:342-344.

30. Orticochea M. A new method of total reconstruction of the penis. Br J Plast Surg 1972;25:347-366.

31. McGregor IA, Jackson IT. The groin flap. Br J Plast Surg 1972;25:3-16.

32. Hester TR, Hill HL, Jurkiewicz MJ. One-stage reconstruction of the penis. $\mathrm{Br}$ J Plast Surg 1978;31:279-285.

33. Song $R$, Gao $Y$, Song $Y, Y u$ Y, Song $Y$. The forearm flap. Clin Plast Surg 1982;9:21-26.

34. Chang TS, Hwang WY. Forearm flap in one-stage reconstruction of the penis. Plast Reconstr Surg 1984;74:251-258.
35. Hage JJ, De Graaf FH. Addressing the ideal requirements by free flap phalloplasty: some reflections on refinements of technique. Microsurgery 1993;14:592-598.

36. Selvaggi $G$, Bellringer J. Gender reassignment surgery: an overview. Nat Rev Urol 2011;8:274-282.

37. Persky L, Resnick M, Desprez J. Penile reconstruction with gracilis pedicle grafts. J Urol 1983;129:603-605.

38. Akhoondinasab MR, Saboury M, Shafaeei Y, Forghani S, Fatemi MJ. The Comparison of A New Durable Coronaplasty Technique with Norfolk Method for Glans Reconstruction after Phalloplasty. World J Plast Surg 2020;9:39-43.

39. Chen ML, Reyblat P, Poh MM, Chi AC. Overview of surgical techniques in gender-affirming genital surgery. Transl Androl Urol 2019;8:191-208.

40. Zuckerman JM, Smentkowski K, Gilbert D, Storme O, Jordan G, Virasoro R, Tonkin J, McCammon K. Penile Prosthesis Implantation in Patients with a History of Total Phallic Construction. J Sex Med 2015;12:2485-2491.

41. Bateman C. World's first successful penis transplant at Tygerberg Hospital. S Afr Med J 2015;105:251-252. 